\section{International Scientific Journal Theoretical \& Applied Science}

p-ISSN: 2308-4944 (print) e-ISSN: 2409-0085 (online)

Year: $2017 \quad$ Issue: $03 \quad$ Volume: 47

Published: $30.03 .2017 \quad \underline{\text { http://T-Science.org }}$

SECTION 6. Metallurgy and energy.
V.K. Sorokin

Doctor of Technical Sciences, Professor of «Materials science, technology of materials and heat treatment of metals» Nizhny Novgorod State Technical University n.a. R.E. Alekseev

S.V. Kostromin Candidate of technical Sciences, associate professor of «Materials science, technology of materials and heat treatment of metals»» Nizhny Novgorod State Technical University n.a. R.E. Alekseev

E.S. Belyaev

Candidate of technical Sciences, associate professor of «Materials science, technology of materials and heat treatment of metals» Nizhny Novgorod State Technical University n.a. R.E. Alekseev

\title{
TECHNOLOGY, STRUCTURE AND PROPERTIES OF METALLIC SHEET FILTER MATERIALS
}

\begin{abstract}
The paper considers generalized data on manufacturing processes, structure formation, filter properties of porous sheet materials obtained by the powder metallurgy method. Three varieties of porous materials with a thickness of 0,06 to 0,60 mm were studied: powder, mesh single-layer mesh of 80/720 mesh and three-layer mesh 004, mesh-powder two-layer and three-layer combined nickel materials from nets and carbonyl powder of nickel with sequence of alternating layers "mesh - powder - mesh" and "mesh - powder".

Key words: powder metallurgy, filter material, porosity, bulk density, hydraulic characteristics.

Language: Russian

Citation: Sorokin VK, Kostromin SV, Belyaev ES (2017) TECHNOLOGY, STRUCTURE AND PROPERTIES OF METALLIC SHEET FILTER MATERIALS. ISJ Theoretical \& Applied Science, 03 (47): 85-92.

Soi: http://s-o-i.org/1.1/TAS-03-47-18 Doi: crossef https://dx.doi.org/10.15863/TAS.2017.03.47.18

\section{ТЕХНОЛОГИЯ, СТРУКТУРА И СВОЙСТВА МЕТАЛЛИЧЕСКИХ ЛИСТОВЫХ ФИЛЬТРОМАТЕРИАЛОВ}

Аннотация: В работе рассматриваются обобщенные данные о технологических прочессах изготовления, структурообразовании, фильтровальных свойствах пористых тонколистовых материалов, полученных методом порошковой металлургии. Исследовали три разновидности пористых материалов толщиной от 0,06 до 0,60 мм: порошковые, сетчатые однослойные из сетки 80/720 и трехслойные из сетки 004, сетчатопорошковые двухслойные и трехслойные комбинированные никелевые материаль из сеток и карбонильного порошка никеля с последовательностью чередования слоев «сетка - порошок - сетка» и «сетка - порошок».

Ключевые слова: порошковая металлургия, фильтрматериал, пористость, насыпная плотность, гидравлические характеристики.
\end{abstract}

\section{Введение}

Пористые материалы со сквозными поровыми каналами используют для фильтрования рабочих сред в различных системах машин и аппаратов, суспензий в химической промышленности и других назначений [1]. В работе рассматриваются обобщенные данные о технологических процессах изготовления, фильтровальных структурообразовании, свойствах пористых тонколистовых материалов. Материалы получали с использованием порошков ПХ18Н15 ГОСТ 13084-88 отдельных фракций от -20 до $-315+200$ мкм, карбонильного никеля ГОСТ 9722-79, тканых никелевых сеток 004 ГОСТ 6613-73 с квадратной ячейкой и 80/720 ТУ 16-538.982-75 саржевого переплетения. Исследовали три разновидности пористых материалов толщиной от 0,06 до 0,60 мм: порошковые, сетчатые однослойные из сетки 


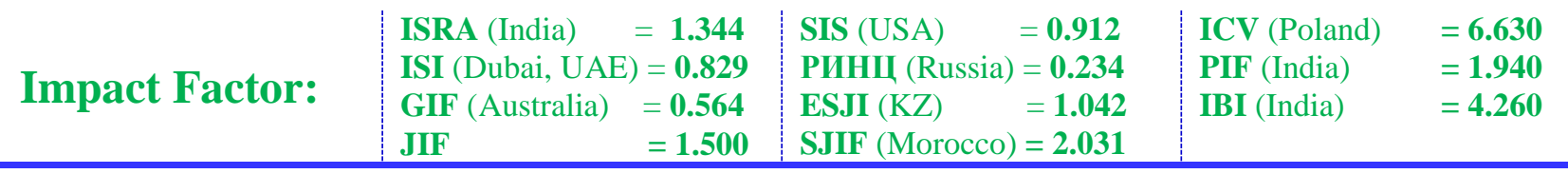

80/720 и трехслойные из сетки 004, сетчатопорошковые двухслойные и трехслойные комбинированные никелевые материалы из сеток и карбонильного порошка никеля с последовательностью чередования слоев «сетка порошок - сетка» и «сетка - порошок».

В опытном порядке изготовляли трехслойный материал с чередованием слоев «порошок - сетка 004 - порошок» и пятислойный материал «сетка порошок - сетка - порошок - сетка». Ленты с наружными порошковыми слоями при испытаниях на перегиб выдерживают до образования макротрещин меньшее число перегибов.

\section{Технологические схемы изготовления материалов \\ При разработке пористых листовых материалов толщиной от 0,06 до 0,60 мм}

использовали различные технологические схемы изготовления (рис. 1). Порошковые и сетчатые слоистые материалы формовали в пористые листы способом прокатки в валках с последующим спеканием. Сетчатые материалы дополнительно уплотняли холодной прокаткой с большими степенями обжатия по толщине для уменьшения размеров поровых каналов.

Сетчато-порошковые материалы формовали способом вибрационного насеивания на движущуюся сетку высокопористого слоя порошка карбонильного никеля с дальнейшим предварительным спеканием. Далее двухслойную ленту плакировали следующим слоем сетки со стороны порошкового слоя. Полученную трехслойную ленту калибровали прокаткой на заданную толщину и проводили окончательное спекание.

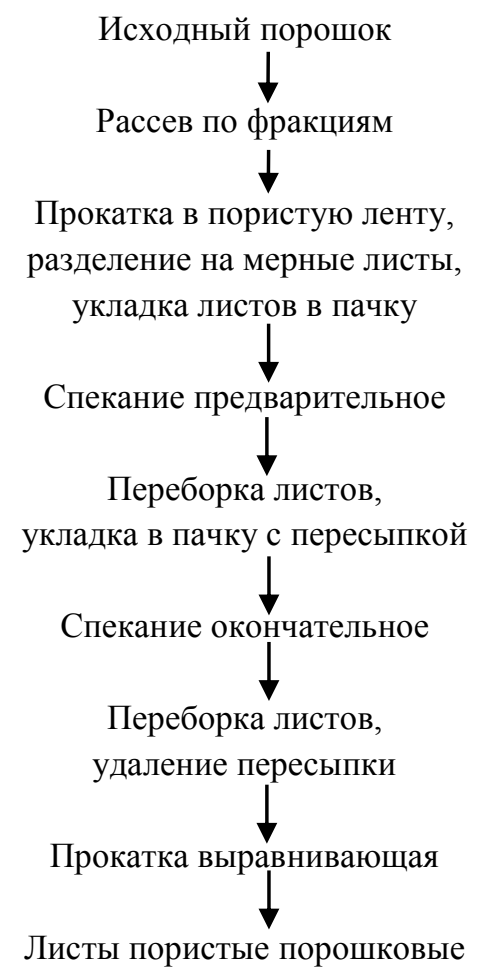

a)

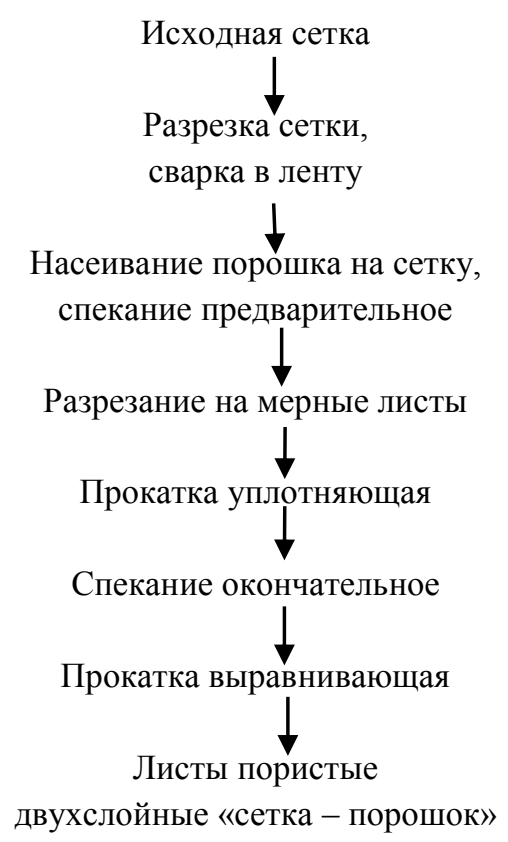

б)

Рисунок 1 -. Технологические схемы изготовления пористых порошковых листов (a) и пористых двухслойных порошково-сетчатых листов (б).

Порошки ПХ18Н15 прокатывали в пористую ленту на дуо-стане с горизонтальным расположением валков, имевших бочку диаметром 75 мм и длиной 110 мм. Пачки листов помещали в контейнер и спекали в камерной электрической печи в два этапа: предварительно при температуре $850 \ldots 950^{\circ} \mathrm{C}, 3$ ч. и окончательно при температуре $1000 \ldots 1150^{\circ} \mathrm{C}, 3$ ч. Сетчатый материал из сетки 004 изготовляли по двух стадийной технологии прокатки: холодная прокатка в брикет толщиной 0,09 мм из трех слоев сетки, уплотняющая и калибрующая прокатка пакета из трех брикетов до толщины листов 0,06...0,08 мм, спекание при температуре $1100^{\circ} \mathrm{C}, 2$ ч. Никелевую сетку 80/720 прокатывали до получения толщины 0,07...0,09 мм 


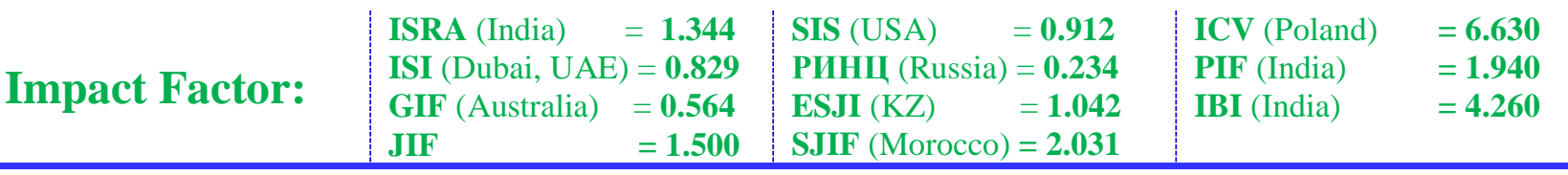

с промежуточными отжигами при температуре $1100^{\circ} \mathrm{C}, 3$ ч.

Пористые сетчато-порошковые листовые материалы изготовляли двух разновидностей с использованием сеток 004 или 80/720 и порошков карбонильного никеля, имевших насыпную

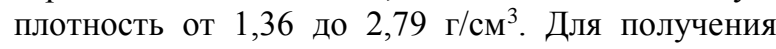
двухслойной ленты-заготовки «сетка порошковый слой» применяли лабораторную установку непрерывного вибрационного насеивания порошка на движущуюся сетку и предварительного спекания с припеканием порошкового слоя к сетке-подложке. В состав установки входят устройство, имеющее набор вращающихся и вибрирующих сит-сеток, расположенных в заполненной аргоном закрытой камере, проходная печь с муфелем прямоугольного сечения и водородной атмосферой, моталка для сматывания пористой спеченной ленты-заготовки в рулон.

После предварительного спекания при температуре $850^{\circ} \mathrm{C}$ в течение 0,5 ч. ленту разрезали на листы, которые подвергали холодной уплотняющей и калибрующей прокатке со степенью обжатия по толщине $60 \ldots 80 \%$. Окончательное спекание-отжиг вели при температуре $1100^{\circ} \mathrm{C}, 4$ ч. в среде осушенного водорода. Так изготовляли двухслойный пористый материал с сеткой 80/720. В случае использования сетки 004 после получения спеченной лентызаготовки проводили плакирование следующим слоем сетки 004 со стороны порошкообразного слоя способом совместной прокатки в валках диаметром 180 мм. Затем выполняли окончательную уплотняющую и калибрующую прокатку с заключительным спеканием. По этой технологической схеме получали трехслойный пористый материал «сетка 004 - порошок - сетка 004». Размеры листов $250 \times 1000$ мм.

У материалов исследовали структуру сквозных поровых каналов (пористость, размеры пор, извилистость каналов), фильтровальные свойства (скорость и тонкость фильтрации).

\section{Строение и свойства пористых листовых материалов}

Для описания структуры применяют различные модели пористых сред. Модели поровой структуры тел из порошкообразных веществ оперируют или с частицами скелета тела, или рассматривают размеры и форму пор. Анализ показал, что для рассматриваемых материалов адекватна экспериментальным данным капиллярная модель пористой среды. Ее основными параметрами являются пористость, как интегральная характеристика, размеры пор, извилистость поровых каналов.
Установлено, что у порошковых материалов средний и максимальный размеры поровых каналов с увеличением пористости в диапазоне от 16 до $47 \%$ изменяются по степенным зависимостям. Показатель степени возрастает с увеличением размера частиц исходных фракций порошка ПХ18Н15. Численное значение среднего и максимального размеров поровых каналов в зависимости от фракции порошка и пористости листов находится соответственно в пределах 3...29 и 4...56 мкм. У сетчатых пористых материалов из сетки 004 в зависимости от числа слоев и степени обжатия при холодной прокатке средний и максимальный размеры пор соответственно равны $10 \ldots 35$ и $14 \ldots 41$ мкм (для двухслойного сетчатопорошкового: $2 . .20$ и $7 . .26$ мкм).

Показателем однородности по размеру пор принято отношение максимального $D$ к среднему $d$ размеру поровых каналов. У пористых листов из порошка ПХ18Н15 при толщине 0,13.. .0,53 мм этот показатель равен $1,35 \ldots 1,45$ и остается постоянным в диапазоне пористости 20...43\%. В случае применения более крупных фракций повышение пористости приводит к изменению показателя однородности по размеру пор с 1,9 до 1,5 (у титановых листов $1,2 \ldots 1,3$ ). Для сетчатых материалов из одного слоя сетки 80/720, трех слоев сетки 004, порошково-сетчатых «сетка $80 / 720$ - порошок» и сетка «004 - порошок - сетка 004» отношение максимального к среднему размеру поровых каналов составляет соответственно $1,18 \ldots 1,19,1,25 \ldots 1,50,1,16 \ldots 1,40$, $1,40 \ldots 1,60$.

Одной из структурных характеристик пористых материалов является коэффициент извилистости $a$ поровых каналов, характеризующий возрастание их длины по сравнению с толщиной. Анализ литературных данных показывает, что по вопросу о роли коэффициента извилистости сквозных поровых каналов у исследователей нет однозначного подхода. В ряде работ [2, 3] вопрос об извилистости пор не рассматривается или эти данные носят отрывочный характер. Необходимость учета коэффициента извилистости пор преимущественно на примерах волокнистых пористых материалов рассмотрена в работе [4].

Исследования тонколистовых материалов показали, что коэффициент извилистости поровых каналов порошковых материалов равен 1,7 ..2,5 при пористости $20 \ldots 35 \%$, возрастая до 2,8...3,8 при большей пористости и использовании крупных фракций порошка. Наибольшую величину, равную $4,1 \ldots 6,9$, имеет этот показатель у сетчатых тонколистовых материалов, подвергаемых холодной прокатке с большими обжатиями. 


\begin{tabular}{l|ll|l|ll} 
& ISRA (India) $=\mathbf{1 . 3 4 4}$ & SIS (USA) & $=\mathbf{0 . 9 1 2}$ & ICV (Poland) & $=\mathbf{6 . 6 3 0}$ \\
Impact Factor: & ISI (Dubai, UAE) $=\mathbf{0 . 8 2 9}$ & PUHU (Russia) $=\mathbf{0 . 2 3 4}$ & PIF (India) & $=\mathbf{1 . 9 4 0}$ \\
& GIF (Australia) & $=\mathbf{0 . 5 6 4}$ & ESJI (KZ) $=\mathbf{1 . 0 4 2}$ & IBI (India) & $=\mathbf{4 . 2 6 0}$
\end{tabular}

Установлено, что численное значение коэффициента извилистости поровых каналов одновременно характеризует однородность пористых материалов по ориентации пор в объеме физического тела. Этот коэффициент для однородных материалов равен двум. Предложена классификация пористых материалов по двум показателям однородности поровой структуры: по размерам пор и по объемной ориентации поровых каналов [5].

Рассмотрено для данных материалов влияние размерного фактора, представляющего собой отношение толщины листов к среднему размеру частиц порошка, на однородность по величине пор

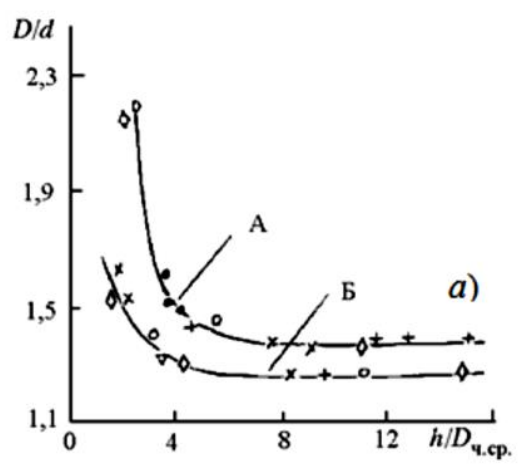

и на коэффициент извилистости (рис. 2). При величине этого фактора более восьми показатель однородности по размеру пор имеет постоянное значение, а при уменьшении менее восьми его численное значение возрастает. С увеличением толщины листов и снижением пористости с $38 \ldots 40$ до $25 \ldots 34 \%$ коэффициент извилистости уменьшается. Так, при размерном факторе, равном 39, коэффициент извилистости поровых каналов достигает величины 1,11 и приближается к расчетному значению 1,065, получаемому по глобулярной модели пористой фиктивной среды при величине пористости $25,9 \%$.

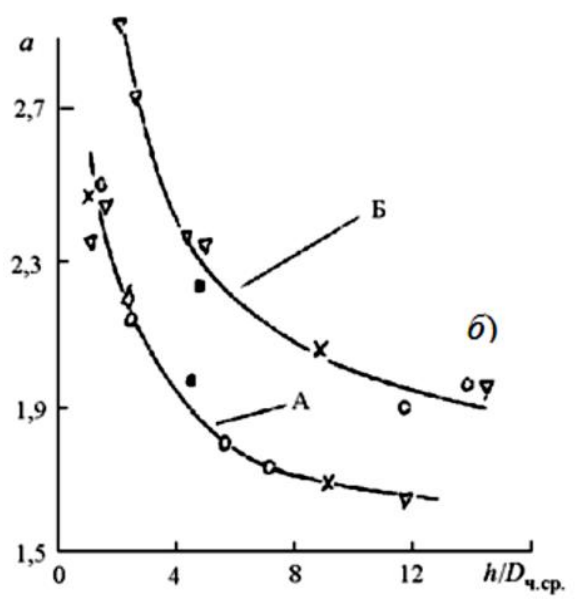

Рисунок 2 - Зависимости показателя $D / d(a)$ и коэффициента извилистости $a$ поровых каналов (б)

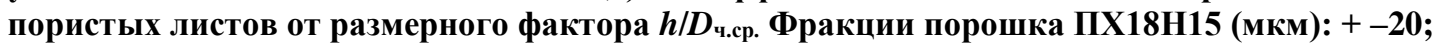

$\bullet-40+20 ; \nabla-63+40 ; \times-100+63 ; \diamond-160+100 ;$ о-200+160. Пористость, \%: А - 32...34; Б -

$38 . .40$.

Установлено, что у пористых тонколистовых материалов из порошков стали и титана гидриднокальциевого восстановления при изменении количества более крупных фракций в порошке, толщины и пористости листов в некоторых пределах одновременно меняются в одном и том же направлении размеры поровых каналов и их коэффициент извилистости. Это обеспечивает своеобразное саморегулирование задерживающей способности таких пористых материалов по отношению к частицам загрязнителя при фильтровании жидких и газообразных сред, то есть высокую стабильность заданной тонкости фильтрации.
Экспериментальные исследования показали, что коэффициент проницаемости К в зависимости от пористости тонколистовых материалов изменяется по степенной зависимости. Для порошковых материалов показатель степени составляет от 2,8 до 4,35, возрастая при переходе к более крупным фракциям исходных порошков. Оценочные расчеты коэффициента проницаемости могут быть выполнены по известным значениям параметров структуры поровых каналов. Основными регулируемыми факторами являются пористость П, средний размер пор $d$ и коэффициент извилистости поровых каналов $a$ :

$$
K=\Pi d^{2} /\left(32 a^{2}\right)
$$

Показано, что на коэффициент проницаемости материалов, изготовленных из одной и той же фракции порошков, при близких величинах пористости листов, оказывает влияние относительная насыпная плотность (рис. 3). 


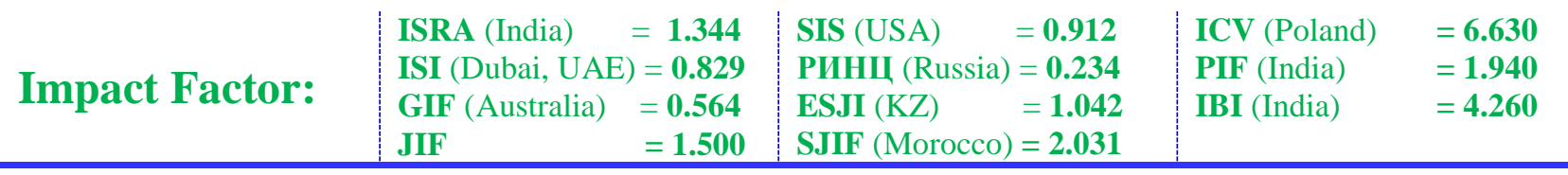

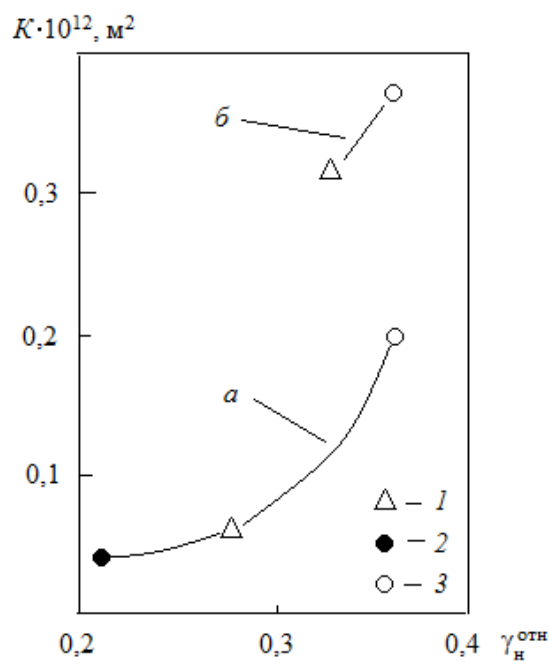

Рисунок 3 - Влияние относительной насыпной плотности порошков фракции $-63+40$ мкм на коэффициент проницаемости пористых листов: 1 - ПХ18Н15; 2 - титан гидридно-кальциевый; 3 - титан электролитический. Пористость листов, \%: а - 28...29; б - 35...36.

Наблюдаемая закономерность обусловлена изменением степени разветвленности поверхности частиц и, соответственно, поровых каналов материалов. Численные значения относительной насыпной плотности порошков можно рассматривать как косвенный показатель разветвленности (шероховатости) поверхности поровых каналов пористых порошковых материалов. Снижение насыпной плотности характеризует большую разветвленность поверхности пор. Больший коэффициент проницаемости при равных значениях пористости имеют пористые сетчатые материалы с малошероховатой поверхностью.

В работе [6] показано, что насыпная плотность порошков $\gamma_{\text {н }}$ зависит от удельной поверхности частиц порошка $S$. Рост удельной поверхности приводит к снижению насыпной плотности, например, порошков меди, полученных электролизом. Некоторые данные о соотношении

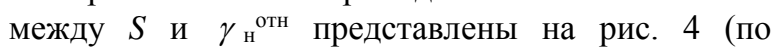
работам Аксенова Г.И. и Ревякина В.П.).

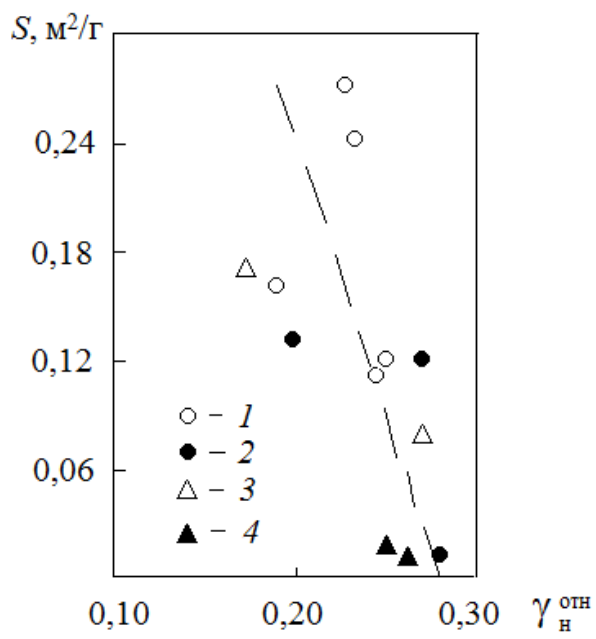

Рисунок 4 - Соотношение между удельной поверхностью и относительной насыпной плотностью металлических порошков: 1 - железо; 2 - никель; 3 - медь; 4 - АПС

В работах $[1,7, \quad 8]$ исследованы гидравлические характеристики в критериальной форме пористых проницаемых материалов типа ФНС из порошков ПХ18Н15 в сравнении с 


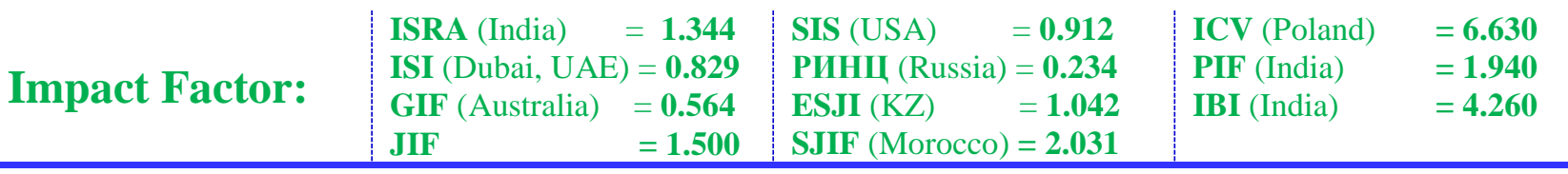

материалами из пористой бронзы и стали 50Х из порошков с сферическими частицами. На рисунке 5 приведены данные для листового материала марки ФНС-10 промышленного производства (ТУ 14-1-2819-79).

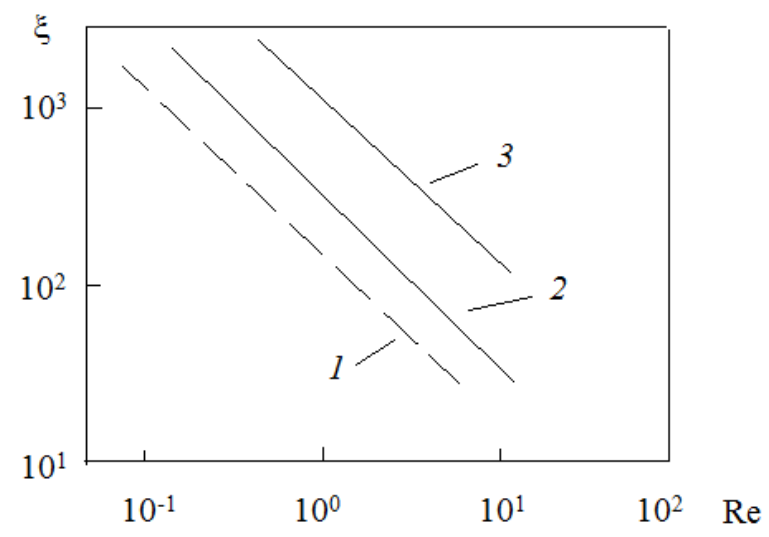

Рисунок 5 - Зависимость коэффициента гидравлического сопротивления $\xi$ пористой бронзы, изготовленной из сферических частиц (1), и материала ФНС-10 из порошка ПХ18Н15 фракции -100+63 мкм, по данным [7] (2) и [8] (3) от числа Рейнольдса Re

Как видно, имеют место расхождения в значениях $\xi$ при одинаковых величинах числа Рейнольдса $\operatorname{Re}$ для материала разных партий одной марки ФНС-10. Сравниваемые партии материала исследованы в 1974 г. и 1984 г., т.е. изготовлены в разные годы. Предположительно, они получены из порошков ПХ18Н15 с различной насыпной плотностью. Данные о насыпной плотности в рассматриваемых работах [7, 8] не приведены. Эти сведения необходимы при анализе закономерностей проницаемости пористых материалов.

При исследованиях задерживающей способности пористых тонколистовых материалов по отношению к частицам загрязнителя при фильтровании жидких сред изучали их дисперсный состав обычно в интервалах размеров $0 \ldots 3,3 \ldots 5,5 \ldots 10$, более 10 мкм. С возрастанием пористости листов и, соответственно, размера поровых каналов выше некоторого значения обычно увеличивается количество частиц загрязнителя более крупных фракций.

В случаях использования для изготовления тонколистовых пористых материалов дисперсных порошков гидридно-кальциевого титана, карбонильного никеля и мелких фракций порошка ПХ18Н15 задерживается 90\% и более частиц загрязнителя размером менее 2 мкм. У листов из порошка ПХ18Н15 крупных фракций количество частиц загрязнителя размером менее 3 мкм сохраняется на уровне $60 . .75 \%$. Лучшую задерживающую способность имеют пористые материалы из порошков ПХ18Н15, полученных с использованием исходного мелкодисперсного порошка карбонильного железа и имеющих пониженную насыпную плотность.

На дисперсный состав частиц загрязнителя, проходящих через поровые каналы, оказывает влияние насыпная плотность порошков ПХ18Н15, характеризующая разветвленность поверхности пор. Для листов толщиной $0,15 \ldots 0,19$ мм при пористости $36 . .38 \%$ из порошка фракции $-63+40$ мкм увеличение насыпной плотности от 1,35 до

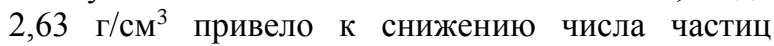
загрязнителя размером менее 3 мкм от 94 до 62\% (рис. 6, a). Номинальная тонкость фильтрации при этом сохранилась на уровне 5 мкм. 


\begin{tabular}{|c|c|c|c|c|c|c|}
\hline Impact Factor: & $\begin{array}{l}\text { ISRA (India) } \\
\text { ISI (Dubai, UAE } \\
\text { GIF (Australia) } \\
\text { JIF }\end{array}$ & $\begin{array}{l}=1.344 \\
=0.829 \\
=0.564 \\
=1.500\end{array}$ & $\begin{array}{l}\text { SIS (USA) } \\
\text { PИНЦ (Russia) } \\
\text { ESJI (KZ) } \\
\text { SJIF (Morocco) }\end{array}$ & $\begin{array}{l}=0.912 \\
=0.234 \\
=1.042 \\
=2.031\end{array}$ & $\begin{array}{l}\text { ICV (Poland) } \\
\text { PIF (India) } \\
\text { IBI (India) }\end{array}$ & $\begin{array}{l}=6.630 \\
=1.940 \\
=4.260\end{array}$ \\
\hline
\end{tabular}
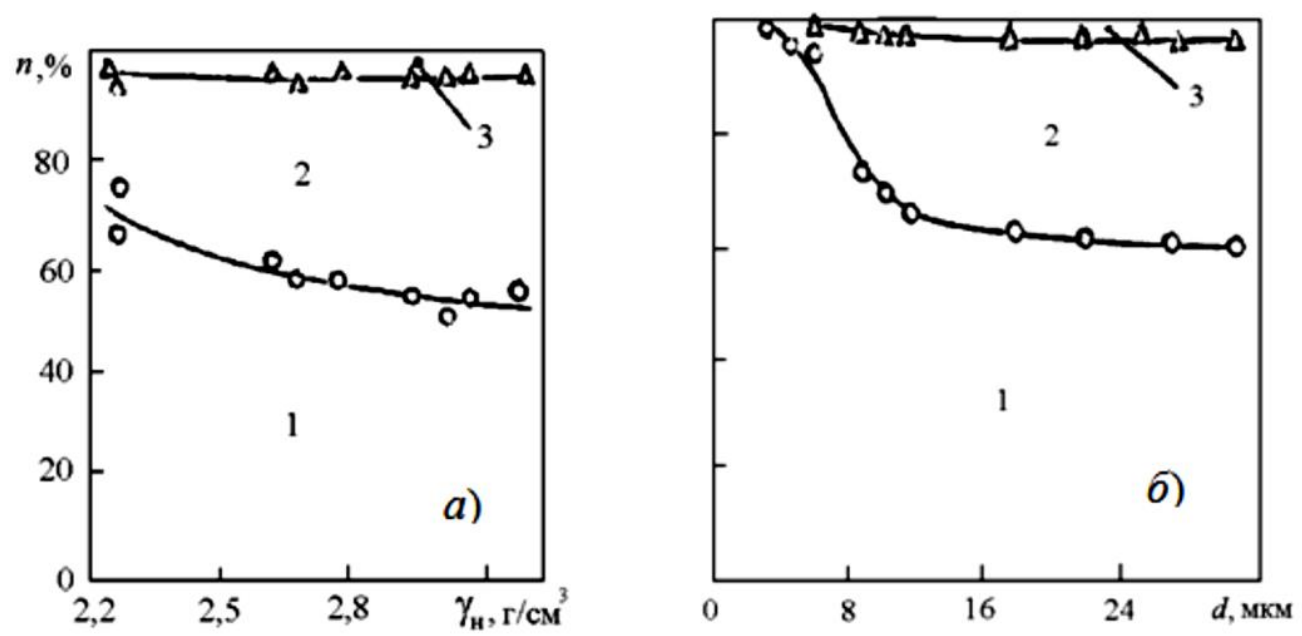

Рисунок 6 - Диаграммы зависимости дисперсного состава $n$ частиц загрязнителя от насыпной плотности порошка ПХ18Н15 фракции -63+40 мкм (a) и среднего размера пор (б). Размерные интервалы частиц загрязнителя, мкм: 1 - менее $3 ; 2-3 . . .5 ; 3-5 . .8$.

Анализ экспериментальных данных показал, что пористые листы из порошков разных фракций, имевшие одинаковую величину поровых каналов при близких значениях коэффициента извилистости, обеспечивают получение практически одинакового дисперсного состава частиц загрязнителя, проходящих через поры листов.

Изучена зависимость дисперсного состава частиц загрязнителя, проходящих через поры, от среднего размера поровых каналов листов из отдельных фракций порошка ПХ18Н15 в диапазоне 4...30 мкм. С увеличением величины пор от 7 до 11 мкм число задерживаемых частиц загрязнителя размером менее 3 мкм снижается от $96 . .98 \%$ до $65 \%$, а далее изменяется незначительно (рис. 6, б).

Анализ взаимосвязи между абсолютной тонкостью фильтрации $\mathrm{A}_{a}$ и максимальным размером $D$ поровых каналов в интервале от 4 до
36 мкм для пористых листов из порошка ПХ18Н15 показал наличие степенной зависимости $\mathrm{A}_{\mathrm{a}}=0,26 D^{1,21}$. Такой характер имеет и функциональная связь между номинальной тонкостью фильтрации (фракционный коэффициент отфильтровывания 0,97$)$ и средним размером поровых каналов у материалов ФЭП из фторлона-4 [9] и фильтровальных бумаг марок АФБ-5 и БФДТ [10].

\section{Заключение}

Примененные технологические схемы позволяют получать различные виды порошковых, сетчатых и сетчато-порошковых пористых листовых материалов. Рассмотрены структурные характеристики поровых каналов и фильтрующие свойства. Материалы применены при изготовлении фильтровальных устройств для тонкой очистки от частиц механических примесей [11-13].

\section{References:}

1. (1987) Poristyye pronitsayemyye materialy: Sprav. izd. / Pod red. S.V. Belova - M.: Metallurgiya, 1987. - 335 p.

2. Shibryayev BF (1982) Poristyye pronitsayemyye spechennyye materialy / B.F. Shibryayev - M.: Me-tallurgiya, 1982. - 168 p.

3. Vityaz' NA (1987) Poristyye poroshkovyye mate-rialy i izdeliya iz nikh / N.A. Vityaz', V.M. Kaptse-vich, V.K. Sheleg - Minsk: Vyssh. shk., 1987. - 167 p.
4. Kostornov AG (1983) Pronitsayemyye metalliche-skiy volokonnyye materialy / A.G. Kostornov - Kiyev: Tekhnika, 1983. - 128 p.

5. (2002) Proizvodstvo poroshkovogo prokata / Pod red. V.K. Sorokina. - M.: ZAO «Metallurgizdat», 2002. - 296 p.

6. Andriyevskiy RA (1991) Poroshkovoye materialo-vedeniye / R.A. Andriyevskiy. - M.: Metallurgiya, 1991. - 205 p. 


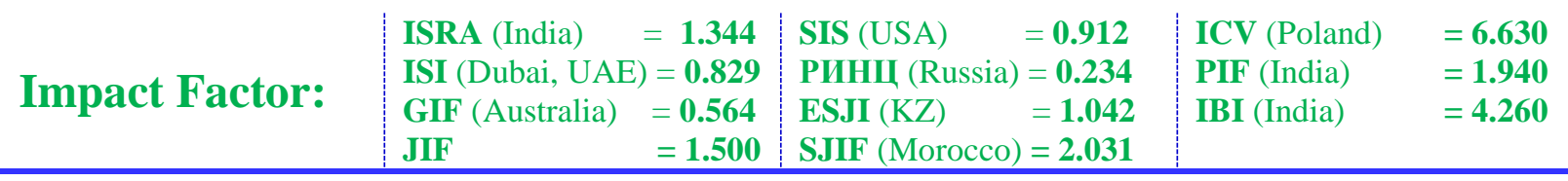

7. Lozhkin VA (1977) Ekspluatatsionnyye kharakte-ristiki poristykh fil'troval'nykh lent tipa FNS / V.A. Lozhkin, S.V. Belov, V.P. Kovalenko i [dr.] // Poroshkovaya metallurgiya. - 1977. - № 2. - p. 84-87.

8. Belov SV (1986) Strukturnyye, gidravlicheskiye i fil'troval'nyye kharakteristiki poristykh lent tipa $\Phi H C$ / S.V. Belov, L.S. Shmelev, V.S. Spiri-donov i [dr.] // Poroshkovaya metallurgiya. - 1986. - № 3. - p. 76-82.

9. Kuvarzin IN (1976) Fiziko-mekhanicheskiye svoystva fil'troval'nykh materialov iz ftorlonov / I.N. Kuvarzin, K.YA. Lesnoy, V.A.Lozhkin i dr. // Plasticheskiye massy. - 1976. - № 6. - p. 49-51.

10. Nevolin VF (1985) Novyye fil'troval'nyye vi-dy bumagi dlya ochistki masla, topliva i vozdukha in internal combustion engines/ V.F. Nevolin, V.V. Khovanskiy // Dvigatele-stroyeniye. 1985. - № 7. - p. 31-33.

11. Belyanin PN (1982) Promyshlennaya chistota mashin / P.N. Belyanin, V.M. Danilov - M.: Mashi-nostroyeniye, 1982. - $221 \mathrm{p}$.

12. Rybakov KV (1982) Aviatsionnyye fil'try dlya topliv, masel, gidravlicheskikh zhidkostey i vozdukha / K.V. Rybakov, YU.I. Dmitriyev, A.S. Polyakov - M.: Mashinostroyeniye, 1982. $-103 \mathrm{p}$.

13. Timirkeyev RG (1986) Promyshlennaya chistota i tonkaya fil'tratsiya rabochikh zhidkostey letatel'-nykh apparatov / R.G. Timirkeyev, V.M. Sapozhnikov - M.: Mashinostroyeniye, 1986. - 152 p. 